\title{
A Brief Discussion on the Positive Influence of "Big Data" on the Teaching of the Course of Law Introduction
}

\author{
Liang Yudong \\ Sichuan University of Arts and Science, Dazhou, Sichuan, 635000
}

Keywords: Generality of Law, Teaching, Difference, Fragmentation, Big Data

\begin{abstract}
There is a certain difference between the purpose of training the course of the general law and its own jurisprudence. This difference has not been concerned and valued by the academic circles, but also embodies in teaching contents, methods, evaluation methods and teaching material arrangement, which directly leads to the poor teaching effect. Big data, rich in content and varied in form, has a positive role in teaching the course of the law introduction. If the advantages of big data are fully utilized, it is possible to alleviate the difference.
\end{abstract}

\section{Introduction}

The so-called "large data" mainly refers to the new technology system for the acquisition, storage, management, analysis, mining and application of massive data. It is a technology derived from the Internet application, that is, Internet Co, such as Facebook, Baidu, Google and so on, which generate and accumulate data on user's network behavior during daily operation, such as shopping, user registration, browsing traces and so on [1]. The size of these data is so large that it can not be used as a measure of the number of units such as $T$ or $G$. Large data have the characteristics of large amount of data, variety, association, low value density and fast speed. And the influence of these characteristics to the society is gradually recognized by people [2-3]. Currently, in the field of government road traffic control, crime control, epidemic trend analysis and other fields, big data has been widely promoted and applied, and people's daily behavior and social life are changing gradually. In March 29, 2012, the Obama administration in the United States "big data research and development plan" proposed by mobile phone, data processing complex, to gain knowledge and insight, from the ability to ascend, to speed up the pace of new scientific and engineering fields, strengthen homeland security, education and learning mode " and the for the future of the new oil" [4]. A big data age has come. In this context, how will we objectively recognize and actively respond to the challenges posed by large data to law education? To this end, we intend to consider and analyze the positive impact of big data on the course of the course of law.

\section{The Internal "Difference" in the Course Teaching of the General Law}

Introduction to law is a legal basis for students of professional courses of non-colleges, the purpose is to guide students in adhere to the Marx doctrine, Mao Zedong thought and China characteristic socialism basic position, viewpoint and method on the basis of theory and practice, learning and mastering the basic theory and legal principle, China's current legal the system of international law and basic knowledge of law, the correct understanding of the construction of the rule of law spirit, and in social practice consciously abide by the law, usage, do China socialist qualified citizens characteristics.

However, the law is a professional, practical very strong discipline, it has its own unique language, logic, method and course system, and behind the system, rules, the theory contains a series of social orderly, healthy and sustainable interaction must rely on and follow the pursuit of value. We know that any subject has its own specific research objects and methods. Law is based on the specific social behavior and social relations, and the object of French speaking is bound to be related to the things in the society. Such as real estate, trademark, patent, company, bill and so on [5]. However, there are some differences in the definition and application of specific concepts. For 
example, a non - Legal non - legal student can not understand this concept and can not find the specific meaning of the concept in daily life. However, when it comes to "courageous" and "good people", people will never feel strange. Whether or not to manage, or to be righteous, it also points to the social relationship that people do when they do things that are good for others. However, there are some legal concepts that can not be expressed in the language of daily life with specific words, but people know what they mean [6]. Such as "unjust enrichment" and so on. At the same time, the legal language is not only different from the daily language in concept, but the legal language is more distinct in the logical structure of the language. The logical structure of the legal language is generally based on "if..." So... Or, otherwise... ". The expression of the propositional form. For example, if someone secretly takes the property of someone else's legal amount secretly for the purpose of illegal possession, his behavior will be identified as theft and bear the corresponding criminal responsibility. For another, ownership is an exclusive and dominant property right. Therefore, no one can infringe upon the right and norm, otherwise the right person will be held accountable for tort liability. And we are not so strict in organizing language and expression in our daily life [7-8]. At the same time, the law also has a unique set of knowledge system for the applicable methods of law. It mainly involves the whole process of the judge's trial. The judge affirms the facts of the case through auditing the evidence materials, and makes legal interpretation of the applicable legal provisions and rules on this basis, striving for similar cases. In some difficult and complex cases, judges should consider not only the above factors, but also the trade-off and balance between the many values of legal pursuits involved in cases, and strive to achieve maximum judicial justice. Therefore, it is said that law is not only a technology, but also an art is also an important factor in the jurisprudence and other social sciences [9].

It can be seen that there is a certain distance between the teaching purpose of the course of introduction to law and the nature of the introduction of law, that is, a law course is a basic course for law majors. The particularity of law knowledge in language, logic system, content and method makes the non-law major students face the professional barriers caused by the pursuit of law and French language and its pursuit of thinking and value. This sense of distance runs through all aspects of the whole teaching activities, and becomes the breakthrough point for us to examine the current teaching activities of the general course of law.

\section{The Face of the "Difference" in the Course of the Introduction of Law}

\subsection{The fragmented tendency of the teaching content in the introduction of law}

Legal knowledge is a knowledge system based on the internal logic of things. Any part of content will lead to difficulties in understanding and explaining legal phenomena and solving legal problems. In the actual teaching process, due to the difference in professional degree of law knowledge, students tend to have a selective acceptance of knowledge in the process of learning. Those who are not professional enough, such as the constitution, or have close ties with their daily lives, such as marriage law, or legal knowledge that has certain interest in related laws, such as criminal law, will be understood and grasped by students. On the contrary, such as anti-monopoly law, negotiable instruments law, contract law and other legal knowledge, professional and strong, difficult because of the language and with students' daily life related degree is not high, the students have not paid much attention and attention. In addition, students tend to learn and understand legal knowledge with their non-legal professional thinking and methods, think and analyze legal problems and legal phenomena, which leads to no way to face legal cases [10]. Thus, the students' frustration in learning legal knowledge is more serious. The tendency of selective learning is more obvious. In this way, the students' understanding and mastery of the whole teaching content have been deepened.

\subsection{The simplification of classroom teaching methods in the introduction of law}

At present, the teaching method is more used in the course of the general law of law. Although teachers realize the importance of interaction, communication and discussion between teachers and 
students and students, teachers should pay attention to the completion of teaching schedule and content. Their interactive design is not complete enough, and students' participation in interaction preparation is not enough, so the quality of teaching interaction can be imagined. Therefore, the introduction of law in the classroom is still mainly a one-way, single, static teaching of teaching activities. The teaching method of single teaching method can not effectively activate students' legal professional thinking, and lack professional thinking to understand and explain legal phenomena and problems, which is not helpful for students to learn professional knowledge of law.

\subsection{The heavy result tendency of the evaluation of classroom teaching in the outline of law}

With the increasingly standardization, procedure, standardization and institutionalization of law education and teaching activities, teaching evaluation has become the final evaluation of the whole teaching process and effect as an important part of teaching activities. Subject orientation, course setting, teaching objectives, teaching content and teaching methods are the basic criteria for their evaluation. The process of teaching evaluation should not be ignored. However, the evaluation of the teaching effect of the introduction to law is still mainly based on the evaluation method of theoretical teaching, that is, a paper or a summary report and so on to evaluate the learning effect of students. This static and result oriented evaluation method makes the teaching activities digitized and stylized is not really objectivity [11]. It is compatible with the specialized teaching content and teaching style, and this teaching evaluation causes teachers to pay more attention to teaching professional knowledge and ignores the non legal professional background and advantages of students.

\subsection{The teaching materials of the general law can not really meet the learning requirements of non-legal students.}

Teaching material is an important reference for students to learn professional knowledge. However, although there are many kinds of textbooks in the present survey of law, there is a basic pattern of pattern arrangement and a single knowledge content. Taking a national level planning textbook as an example, it is divided into two parts: professional knowledge and thinking problem corresponding to this knowledge. In terms of professional knowledge, most of them are related to the collection of relevant legal knowledge, lack of further explanation and materialization of these contents, and no effective analysis and explanation of relevant laws and regulations through specific cases [12]. Investigate its reason, scholars do not recognize the nature of the course introduction to law and non-law students "differences", making the materials in the preparation of more reflects the tendency of professionalism, while ignoring the students may exist in non-legal professional legal knowledge to accept the difficulties, causes the student to test for the purpose of learning. Rote learning is the main learning method, while the understanding and application of knowledge itself is ignored and the teaching effect is not ideal.

Therefore, the traditional teaching of introduction to law did not really understand and solve the knowledge of professional and non-professional students' background of law exists between the "difference", professional teaching does not exert students legal knowledge, stimulate students interest in learning and initiative. Passive and instilled teaching leads students to take formal attitude to the course teaching activities.

\section{The Positive Role of Large Data in the Teaching of Law Introduction}

After all, law is different from other professional knowledge, which is an objective existence. Then the inherent differences exist only in the face of introduction to law in the course of solution is possible in various ways, through the knowledge of law means to reduce this professional color, through a variety of ways and methods to alleviate the difficulty of students learning the professional knowledge of law. Large data provide us with such resources and possibilities.

The Internet has deeply influenced and penetrated into every corner of human daily life. Human life, work and social interaction have been increasingly integrated with the Internet. Computers, mobile phones, all kinds of Internet chat tools, online shopping have become the important media, 
tools and life content of every person's daily life. The traces left by the various activities that people carry through the Internet will be displayed in the form of data. The contents and types of data derived from our daily social life are also exceptionally rich. The result of collecting, storing and accumulating these data is the result of large data. But this is not the only characteristic of big data, more important is a lot of data of these data is not out of order, without a clue, but can be in a variety of topics under these non-organized data to be associated with the type of form with texts and images and audio, video and other forms of performance [13]. It can be seen that the large data not only lies in the huge amount of data, but also has the characteristics of relevance and diversity. According to these characteristics, we will analyze and discuss the positive effect of big data on the teaching activities of the course of law introduction.

\section{1 "Big data" provides rich resources for teaching content, and promotes the further integration of teaching content}

From the above statement, we can see that there is a difference between the professionalism of legal knowledge and its non-professional nature. To narrow this gap, we need various ways and means to solve it. The first problem is the legal language translated into everyday language and living language, will be hard to understand and abstract language becomes vivid and specific. Under the background of big data, data has various forms of expression and reflects the vividness and situational characteristics of people's daily life, making this goal no longer distant. In the actual teaching process, we can set specific knowledge for the evolution of specific topics, the relevant knowledge to be specific through a series of cases, video and data, makes the students to understand and master the knowledge of law is the basic social imagination and examples of, ease caused by the professional textbooks trouble.

At the same time, big data can not only provide plenty of vivid and real cases for the teaching of law generality course, but also help students understand and integrate relevant knowledge in the process of learning legal knowledge. This is mainly due to the structural characteristics of large data, that is, under specific topics, a large number of cases in a certain time span can be obtained. These cases will be showing the similarities and differences and changes in the spatial and temporal dimensions of these similarities and differences in the evolution, makes students have a deeper and more comprehensive understanding of specific knowledge, and inspire students to think and try to answer these questions in the show case [14]. In this way, the students will sort out and summarize the relevant knowledge of the subject as the basic basis and reference for thinking and answering these questions. For example, when we talk about the theme of running a country according to law, we can pick out some real cases that have certain influence under their specific social and historical background, and sort out and process them in chronological order according to the data provided by big data. Based on these cases demonstrate and explain, you can sort out the basic legal construction of our country basic vein Road, through regulating and limiting the power to establish the authority of law, enhance the trust of the people, the legal protection of human rights and through faith, so as to maximize consensus, gathering people, more firm confidence and faith in the rule of law. This will not only make students understand the importance of rule of law, but also further examine the conditions of rule of law, and further consider and explore this theme in the light of the reality.

\section{2 "Big data" increases the feasibility of interactive teaching}

In view of the controversial teaching methods of spoon feeding, such as "teacher talk, student listening and recording", teachers are constantly exploring and trying various ways to change. The extensive development of practical teaching can be said to be the result of this effort. The background of large data provides us with new ideas and ways. In the network of social life, people are not only the sharing of data and consumers, but also their providers and producers. In the process of applying these data to daily social life, we further promote the reproduction of data size and species. People's demand for data is more intense and irreversible. This must be based on a basic premise that the means and ways for people to obtain data will be more convenient, multi-channel and low cost. So in the teaching activities, students and teachers have the opportunity and possibility of obtaining and collecting data resources equally. This provides an objective 
condition for the transformation of teaching methods. Teachers can change the past, the authoritative management role, to transform itself into the teaching activities of the organizers, guides and coordinator; and students are changing from the simple teaching of the status of the audience for the teaching activities of the participants, realize their own subjectivity. Under the guidance of teachers, students can collect data from different angles based on their definite themes, analyze and judge their respective professional backgrounds, and draw an initial conclusion. The teaching activities are promoted by displaying its results in the classroom and by questioning or supporting the other students' results and their related basis. This can effectively promote the students' learning initiative and cultivate students' awareness of rational debate and critical thinking skills, exercise the comprehensive quality of information analysis and processing ability and language ability, and ultimately in the teaching quality and effect evaluation from the objectivity of the evaluation focus on static, the serious result to the subjective evaluation of the dynamic process change in the active teaching atmosphere and promote the upgrading and transformation of the entire teaching activity. More importantly, students can take advantage of their original professional background, think and analyze these cases, and complete collision, communication and interdisciplinary views between law majors and non-law Majors in discussions, refutation, argumentation and reasoning. In this process of rational communication, the characteristics of legal thinking can be really highlighted, and the connotation of legal knowledge can really let the students get experience and comprehend. It can be seen that large data provide a platform for the interactive teaching of the background, resources and communication.

It is worth emphasizing that, while providing a rich teaching resources and content data for the introduction of law teaching, and provides possibilities and conditions for the development of interactive classroom teaching, to provide a space for students to play illegal professional background, inherent "difference" method to shorten the introduction course of play a positive role. However, this does not negate the status and significance of the teaching form and form of traditional law in teaching activities, but is based on the innovation and perfection of traditional teaching methods.

\section{Conclusions}

To sum up, the inherent difference between discipline training purpose and discipline specialization brings a series of troubles to its teaching, and then affects the actual teaching effect. These problems can be alleviated and improved by the huge, structured, and convenient features of data with large data. Of course, big data itself is a new thing to be defined and continue to understand, especially for the negative impact of big data is still insufficient, so the understanding of big data will continue to deepen the understanding of big data, of course, teaching significance and effect on teaching and learning law course also will continue.

\section{References}

[1] Zhang J Y, Xi W U. The Impact of Big Data on English Teaching: Discussion on the Application of Big Data in English Teaching [J]. Contemporary Teacher Education, 2016.

[2] Dr. Mohammed Viquaruddin. Teaching of Social Sciences in Higher Education the Influence of Family Political Discussion on Youth Civic Development [J]. University of Essex, 2012.

[3] Lei H Y, Ying-Ming W U, University T P. Discussion on the Quantitative Analysis Experimental Teaching of Economics and Management Specialty under the Background of Big Data [J]. Journal of Shanxi Institute of Economic Management, 2017.

[4] Yang H. Discussion about the Influence of Western Painting Teaching on the Fine Arts in the Qing Dynasty[C]// International Conference on Education, Language, Art and Inter-Cultural Communication. 2017.

[5] Guo W. Discussion on Criminal Legislation under the Influence of Criminal Law of Enemy in 
China [J]. Journal of Henan Police College, 2017.

[6] Li G, Geng Y, Pang H. A Discussion about the Impact of Vocational Skills Competition on the Teaching Reform in Vocational Colleges[C]// International Conference on Arts, Design and Contemporary Education. 2016.

[7] Zhu Z, Wang X, Li L. Discussion on the Influence of TCP Performance Enhancement (TPE) on Data Service Rate [J]. Guangxi Communication Technology, 2017.

[8] Yang J, Chen T, Zheng L S. The Influence of the Big Data Age on the Teaching of Statistics [J]. Education Teaching Forum, 2017.

[9] Gibbs F W, Reznick J S. Teaching and Researching the History of Medicine in the Era of (Big) Data: Introduction [J]. Medical History, 2017, 61(1):176-176.

[10] Hong-Yan L I, North University China. The Application of Big Data Mining Technology in Computer Basic Course Teaching[C]// Education Teaching Forum. 2017.

[11] Nagar A. Enhancing Teaching of Big Data by Using Real World Datasets[C]// Acm Technical Symposium. ACM, 2016:496-496.

[12] Yun-Peng F U, Fei X U, Ding Y W, et al. Research and practice of innovative teaching mode of statistical papers writing instruction course in the era of big data[J]. Journal of Science of Teachers College \& University, 2016.

[13] Tao T, Jun L I, Chen M D, et al. Teaching Reform and Innovation of Chemistry of Fine Chemicals Course in the Age of Big Data[J]. University Chemistry, 2016.

[14] Hui-Zhao T U, Hao L I, Chen F. Innovative and Participative Seminar Teaching for Transport Big Data Analysis of Master Course [J]. Education Teaching Forum, 2017. 